\title{
Assessing the visual aspect of rotating virtual rose bushes by a labeled sorting task
}

\author{
M. Garbez ${ }^{\text {a }}$, G. Galopin a ${ }^{\text {, M. Sigogne }}{ }^{\text {b }}$, P. Favre ${ }^{\text {b,c }}$, S. Demotes-Mainard ${ }^{\text {b }}$, R. Symoneaux ${ }^{\text {d,* }}$ \\ ${ }^{a}$ Agrocampus Ouest, Centre d'Angers, UMR 1345 IRHS (Agrocampus Ouest, INRA, Université d'Angers), SFR QUASAV 4207, 2 rue Le Nôtre, 49045 Angers Cedex 01, France \\ ' INRA, UMR 1345 IRHS (Agrocampus Ouest, INRA, Université d'Angers), SFR QUASAV 4207, 42 rue Georges Morel, 49071 Beaucouzé, France \\ ${ }^{\mathrm{C}}$ University of Fribourg, Department of Biology, Plant Biology, Chemin du Musée 10, 1700 Fribourg, Switzerland \\ ${ }^{\mathrm{d}}$ Groupe ESA, UPSP GRAPPE, SFR QUASAV 4207, 55 rue Rabelais, BP 30748, 49007 Angers Cedex 01, France
}

\begin{abstract}
Aesthetics is one of the major parameters for consumers when buying a rose bush. Therefore, managing this quality is important for agronomists. Tools are needed to assess visual characteristics and to find links with architectural plant parameters. Sensory analyses were developed using real plants and photographs as stimuli. With technology and modeling improvements, using virtual plants could presents numerous advantages. This study demonstrated the feasibility of using rotating virtual rose bush videos as stimuli for a labeled sorting task. The virtual rose bush reflected a natural within-crop variability of one cultivar based on bud breaks location and axes length. Two panels of subjects closely linked to the horticulture sector sorted and described 40 rotating virtual rose bush videos. Non-metric Multidimensional Scaling (MDS) results for both panels were similar and allowed us to highlight five groups of virtual rose bushes with their specific sensory characteristics and their own most representative products using a combination of the paragons and the most typical products. This approach revealed that subjects detected high visual differences between products, and that by using rotation, they were able to integrate 3D properties about variations around plant facets. Finally, a labeled sorting task is a powerful method for preliminary exploration of the visual aspect of virtual plants.
\end{abstract}

\section{Introduction}

The visual quality of ornamental plants is a specific criterion that plays a major role in the purchase triggering. This quality stands on visual characteristics tightly linked to a $3 \mathrm{D}$ component that is the plant architecture which results from the characteristics and the spatial organization of the aerial organs (Boumaza, DemotesMainard, Huché-Thélier, \& Guérin, 2009; Morel, Galopin, \& Donès, 2009). Impacts of growing practices on some architectural parameters are well-known for numerous plant species. Nonetheless, growers and breeders make use of them more or less empirically, and resulting effects on visual properties from a sensory point of view still poorly studied (Crespel, Le Bras, Relion, \& Morel, 2014; Huché-Thélier et al., 2011).

Recently, Boumaza et al. (2009) transposed the sensory approach to the ornamental field with one of the most famous ornamental plants as model: the rose bush. This approach made it possible to select sensory attributes according their unambiguity,

\footnotetext{
* Corresponding author. Tel.: +33 (0) 2412355 55; fax: +33 (0) 241235500 E-mail address: r.symoneaux@groupe-esa.com (R. Symoneaux).
}

discrimination power, and independence using plants directly as stimuli. For some sensory attributes about shape properties like "top-sided shape", "rounded form", "shape filling" and "plant compactness", the subjects were asked to look only one plant facet: the one with the plant label visible. For the others attributes, subjects were allowed to turn the plants around, but this was not a requirement. Unfortunately, this study did not make it possible to integrate the plant 3D in the reduced final list of sensory attributes. Using single facet picture of plants as stimuli, following sensory studies on rose bushes based on the previous of Boumaza et al., (Boumaza, Huché-Thélier, Demotes-Mainard, Le Coz, \& Nathalie, 2010; Huché-Thélier et al., 2011; Santagostini et al., 2014) have discarded the plant 3D. However, plants have multiple facets, and the sensory perception of this should be investigated. Furthermore, architectural variations among a single rose bush crop composed of plants from the same cultivar and grown in the same conditions could be high (Demotes-Mainard et al., 2013). The implications of this variability among such crops need to be studied to better understand how much this variability could impact plants' visual properties, and to target the key architectural parameters related thereto. 
Using plants from a same cultivar grown in a unique environment recorded on video while rotating as stimuli for sensory evaluations could be therefore an interesting way to investigate: (i) if the human eye can distinguish visual differences among such a crop; and (ii) if it integrates or not the plant 3D for the characterization. For this, using virtual modeling represents an efficient alternative to counteract some limitations that occurs with real plants and photographs like for presenting the plants' various facets or defoliated plants as mentioned by Boumaza et al. (2010). Indeed, virtual plant modeling offers many advantages for various experimental issues (Heuvelink, Tijskens, \& Kang, 2004). It enables a quick generation of large samples that can be visualized and manipulated in 3D on computer screens. Virtual plant growth can be easily monitored, controlled and stopped with various parameters. Also, architectural parameters of virtual plants can be directly obtained from the modeling process, whereas it is very time-consuming and tedious on real plants (Crespel, Sigogne, Donès, Relion, \& Morel, 2013). In addition, using virtual plants does not involve growing costs, and allows taking and moving them readily thanks to data storage devices.

In this context, using Rosa hybrida as a model, our research project aims to better understand the dynamic relationships existing between the architectural construction of the bush and its visual appearance. For this, an objective and suitable method for visual characterization of virtual and real plants that integrate their 3D is needed. In the present paper, a first attempt to use as stimuli virtual rotating plants generated from architectural data of a single rose bush crop for a sensory evaluation of their visual appearance is presented.

The sensory profile derived from the quantitative descriptive analysis $\left(\mathrm{QDA}^{\circledR}\right)$ methodology (Stone, Sidel, \& Singleton, 1974) is a well-known suitable tool to explore sensory properties of complex products. It could have been used first, however before establishing a sensory profile, it is important to know if the product space studied presents perceptible differences. Otherwise, there is no reason to do so (Strigler, Touraille, Sauvageot, Barthélémy, \& Issanchou, 2009). This is particularly relevant when studying genetically identical plants grown in the same environment. Thus, a labeled sorting task i.e. a free sorting followed by a verbalization task (Bécue-Bertaut \& Lê, 2011) was preferred for a first attempt. This sensory procedure appears to be a quick and effective way to characterize a such product space, and could provide solid bases for guiding subsequent analyses such as sensory profiles (Chollet, Lelièvre, Abdi, \& Valentin, 2011). The sorting task has been tested on various types of products and has proved itself to be an effective, well-established method that makes it possible to know if a product space shows an underlying perceptual or conceptual structuring. This task requires little time and people who are familiar with the product field but not necessarily trained (Abdi, Valentin, Chollet, \& Chrea, 2007; Chollet et al., 2011; Varela \& Ares, 2012). It is a suitable method to reveal eventual differences and similarities within a large sample. Indeed, Bijmolt and Wedel (1995) showed that when using free sorting compared to other discriminative tasks (paired or triadic comparisons, conditional ranking), subjects expressed less fatigue, less boredom, better task insight, and they took less time to complete the task. Nevertheless, sorting tasks alone do not provide any information about the properties used by the subjects to evaluate the products. Thus, a verbalization task could follow the sorting in order to interpret the eventual underlying structure of the product space (Chollet et al., 2011; Faye, Courcoux, Giboreau, \& Qannari, 2013). Therefore, a labeled sorting task was judged to be an appropriate method to investigate quickly if it is possible: (i) to use videos of rotating virtual plants as stimuli; (ii) to perceive visual differences among plants from a same cultivar and grown in the same conditions; and (iii) to integrate the plant $3 \mathrm{D}$ in the characterization.

\section{Materiel and methods}

\section{Sample collection: Rotating virtual rose bush videos}

Forty rotating virtual rose bush videos (referred to below as virtual rose bushes or products) were collected (see Video 1 for an example of a rotating virtual rose bush video and Fig. 1 for a frame still of this video). To obtain these virtual rose bushes, data from an architectural analysis of five-month old 'Radrazz' (a Rosa hybrida cultivar marketed under the name of Knock Out ${ }^{\circledR}$ ) cultivated under controlled non-restrictive conditions were used (Morel et al., 2009). These data made it possible to create a matrix for a normalized plant that combine according to the location of the buds: (i) the probability of bud break; and (ii) the probability that the bud break give a short or long axis. The matrix and its usage rules presented thereafter, were then implemented in a former virtual plant structural model of the 'Radrazz' cultivar (Favre et al., 2007) built using L-studio, a Lindenmayer system-based plant-modeling software (Karwowski \& Prusinkiewicz, 2004), making it possible to generate rotating plants in silico using a structural and probabilistic model. Then videos of the rotating plants were recorded with CamStudio $^{\mathrm{TM}}$, a free screen-recording software (CamStudio., n.d.).

More precisely, this model considers short and long axes respectively composed of 3 and 9 metamers, each formed by an internode, a node, a leaf and a bud. Axes are edified by vegetative terminal apexes which turn at the end of their growth into flowers and then into fruits. The modeling process starts by the growth of a first branching order 1 long axis. Then, a random selection ordered according to the decreasing bud break probability of each metamer is done to sample which buds give branching order 2 axes. A second random selection is done to sample which bud breaks give long or short axes. At each new branching order edified, the numbers of long and short axes of the current step are compared to respective minimum and maximum threshold values. If thresholds are not fulfilled, the algorithm discards the axes and restarts the random selections on the inferior branching order until it does. Then the process continues until the plant has formed branching order 5 axes.

Since data of Morel et al. (2009) were obtained from plants of the same cultivar grown in the same conditions, the modeling process reflects thus the architectural variability within a similar crop.

\section{Subjects}

Thirty-four volunteers closely linked to the horticulture sector were recruited from the Research Institute on Horticulture and Seeds (RIHS), the French Group for the Study and Control of Varieties and Seeds (GEVES), and the French Institute for life, food and horticultural sciences and landscaping (Agrocampus Ouest), none of whom had followed specific training for this experiment. The subjects were divided into two panels on the basis of their background characteristics (Table 1): panel 1 composed of 16 students (94\% under 26 years old), and panel 2 composed of 18 engineers, researchers and technicians (94\% over 26 years). This strategy was chosen for two reasons: (i) a priori, the two panels differ on the basis of their horticultural product knowledge; (ii) the availably of the subjects did not allow a repetition, thus comparison between panels could be used for the task reproducibility assessment.

\section{Sensory test conditions and procedure}

The test took place in computer labs with identical 17" CRT monitors configured with their optimal preset $1600 \times 1200$ resolution. The subjects were placed on individual workstation sufficiently spaced from each other to avoid communication between them. Virtual rose bushes were coded with three-digit numbers 


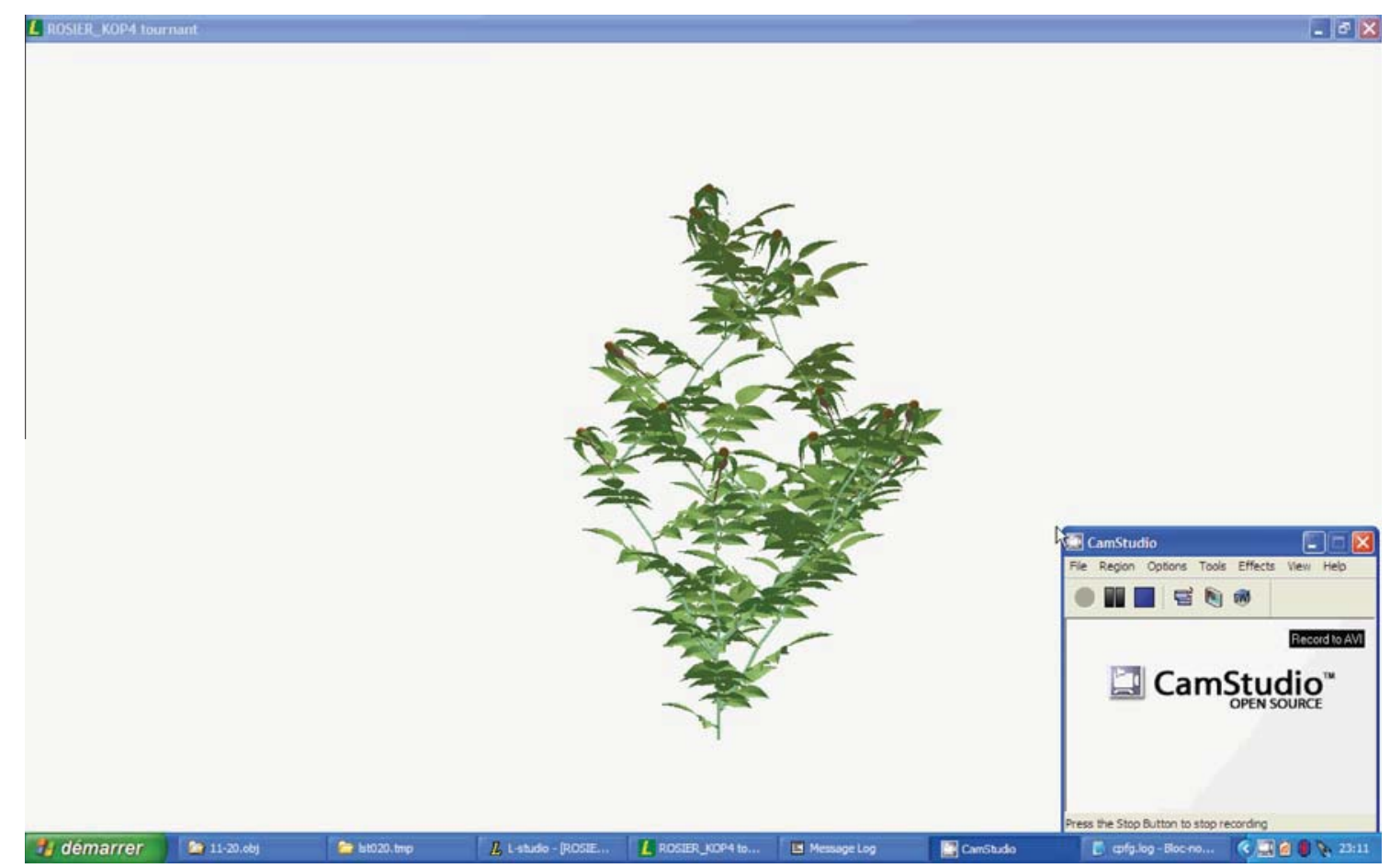

Fig. 1. A frame still in reduced size of a rotating virtual rose bush video (R_20).

Table 1

Distribution of the background characteristics of the subjects for the two panels of Experiment 1.

\begin{tabular}{lll}
\hline & Panel 1 $(\mathrm{n}=16)$ & Panel 2 $(\mathrm{n}=18)$ \\
\hline Age & 15 & 1 \\
$16-25$ years & 1 & 3 \\
$26-35$ & & 8 \\
$36-45$ & & 4 \\
$46-55$ & & 2 \\
$\geqslant 56$ & 7 & \\
Gender & 9 & 14 \\
Female & & 4 \\
Male & 4 & \\
Working on ornamental plants & 12 \\
No & 12 & 6 \\
Yes & & \\
Occupational category & & 6 \\
Engineer/Researcher & 16 & 12 \\
Student & & \\
Technician & & \\
\hline
\end{tabular}

and presented on individual Microsoft ${ }^{\circledR}$ PowerPoint files containing a slide with coded buttons hyperlinked to the virtual rose bush video files. Buttons were displayed from left to right and from top to bottom according to a William Latin square-based design adaptation. Subjects had to click on these buttons to watch associated virtual rose bushes in a pop-up window and had to close it before opening another one.

Subjects were first asked to "sort the virtual rose bushes into homogeneous groups according to their visual similarity (you can make as many groups as you want)" by moving buttons on their own PPT slide. Subjects could see each virtual rose bush as many times as necessary. Then, they were asked to write their groups down on paper and to "give some words to describe and differentiate each group (do not use a drawing or diagram)". So as not to influence the sorting, subjects were not aware of the purpose of the second step before the first one was completed.

\section{Data analysis}

\section{Product mapping and clustering}

Sorting results were encoded in dissimilarity matrices respectively for panel 1, panel 2, and pooled panel, representing for each product pair the number of subjects who did not put them together in a same group. These matrices were then analyzed with a nonmetric procedure of multidimensional scaling (MDS) and the final configurations were selected using a stress scree plot (Faye et al., 2004). Sorting consistency was evaluated by separately analyzing Panel 1 and 2 and then appraising the similarity of their product configurations by the regression vector coefficient (RV) and its statistical significance (Faye et al., 2004; Josse, Pagès, \& Husson, 2008). In parallel, a Hierarchical Cluster Analysis (HCA) was performed with Ward's method on the dissimilarity matrix obtained for the three panel configurations to identify groups of similar virtual rose bushes. In addition, the Rand Index (RI) was computed to quantify the similarity between the partitions of the two panels (Faye et al., 2004; Hubert \& Arabie, 1985).

Then, for the group illustrations, two representativeness notions were combined in order to select a representative virtual rose bush for each group of products: (i) paragons: the products closest to their group center; (ii) the most typical products: products the farthest from the other group centers (Husson, Josse, \& Pagès, 2010). The five best paragons and most typical products were retained within each group. The best paragon among the virtual rose bushes that were given by each group was selected as the most representative of its group.

\section{Description analysis and transcoding for product mapping} interpretation

The description analysis and transcoding followed an adaptation of the method provided by Symoneaux, Galmarini, and Mehinagic (2012) for comment analysis of consumer's likes and dislikes. Five ornamental plant experts read group descriptions in detail and separated each into individual expressions. Experts 
Table 2

Encoding descriptions: examples of data coding for four group descriptions.

\begin{tabular}{|c|c|c|c|c|c|c|c|c|}
\hline Description & Expression & Reduction & Category & $\begin{array}{l}\text { Quant. } \\
\text { mod. }\end{array}$ & $\begin{array}{l}\text { Loc. } \\
\text { mod. }\end{array}$ & $\begin{array}{l}\text { Shape } \\
\text { mod. }\end{array}$ & $\begin{array}{l}\text { Color } \\
\text { mod. }\end{array}$ & Lexical item \\
\hline $\begin{array}{l}\text { Flared habit, open, often } \\
\text { unbalanced habit, } \\
\text { inhomogeneous. }\end{array}$ & $\begin{array}{l}\text { - Flared habit } \\
\text { - Open } \\
\text { - Often unbalanced habit } \\
\text { - inhomogeneous }\end{array}$ & $\begin{array}{l}\text { - Flared } \\
\text { - Open } \\
\text { - Unbalanced } \\
\text { - Inhomogeneous }\end{array}$ & $\begin{array}{l}\text { Shape } \\
\text { Shape } \\
\text { Symmetry } \\
\text { Homogeneity }\end{array}$ & $\begin{array}{l}0 \\
0\end{array}$ & & $\begin{array}{l}\text { Flared } \\
\text { Open }\end{array}$ & & $\begin{array}{l}\text { Shape_Flared } \\
\text { Shape_Open } \\
\text { Symmetry_0 } \\
\text { Homogeneity_0 }\end{array}$ \\
\hline $\begin{array}{l}\text { Denuded base, good branching } \\
\text { (first } \\
\text { branches departure too high). }\end{array}$ & $\begin{array}{l}\text { - Denuded base } \\
\text { - Good branching } \\
\text { - First branch } \\
\text { departure too high }\end{array}$ & $\begin{array}{l}\text { - Denuded base } \\
\text { - Good branching } \\
\text { - Branches high }\end{array}$ & $\begin{array}{l}\text { Branching } \\
\text { Branching } \\
\text { Branching }\end{array}$ & $\begin{array}{l}0 \\
2 \\
2\end{array}$ & B & & & $\begin{array}{l}\text { Branching_0B } \\
\text { Branching_2 } \\
\text { Branching_2A }\end{array}$ \\
\hline $\begin{array}{l}\text { Branching on the whole axis but } \\
\text { symmetric. }\end{array}$ & $\begin{array}{l}\text { - Branching on the whole axis } \\
\text { - But symmetric }\end{array}$ & $\begin{array}{l}\text { - Branching on the whole axis } \\
\text { - Symmetric }\end{array}$ & $\begin{array}{l}\text { Branching } \\
\text { Symmetry }\end{array}$ & $\begin{array}{l}2 \\
2\end{array}$ & $\mathrm{D}$ & & & $\begin{array}{l}\text { Branching_2D } \\
\text { Symmetry_2 }\end{array}$ \\
\hline $\begin{array}{l}\text { Intermediate branching, } \\
\text { unbalanced } \\
\text { plant, less favorable aesthetic. }\end{array}$ & $\begin{array}{l}\text { - Intermediate branching } \\
\text { - Unbalanced plant } \\
\text { - Less favorable aesthetic }\end{array}$ & $\begin{array}{l}\text { - Intermediate branching } \\
\text { - Unbalanced } \\
\text { - Less aesthetic }\end{array}$ & $\begin{array}{l}\text { Branching } \\
\text { Symmetry } \\
\text { Hedonic }\end{array}$ & $\begin{array}{l}2 \\
0\end{array}$ & M & & & $\begin{array}{l}\text { Branching_2 M } \\
\text { Symmetry_0 }\end{array}$ \\
\hline $\begin{array}{l}\text { Dark foliage, red fruits, small size, } \\
\text { slightly branched. }\end{array}$ & $\begin{array}{l}\text { - Dark foliag } \\
\text { - Red fruits } \\
\text { - Small size } \\
\text { - Slightly branched }\end{array}$ & $\begin{array}{l}\text { - Dark foliage } \\
\text { - Red fruits } \\
\text { - Small } \\
\text { - Slightly branched }\end{array}$ & $\begin{array}{l}\text { Foliage color int. } \\
\text { Fruit color } \\
\text { Height } \\
\text { Branching }\end{array}$ & $\begin{array}{l}2 \\
0 \\
1\end{array}$ & & & Red & $\begin{array}{l}\text { Foliage color int._2 } \\
\text { Fruit color_Red } \\
\text { Height_0 } \\
\text { Branching_1 }\end{array}$ \\
\hline
\end{tabular}

Quant. mod. (Quantification trait): 0 (not); 1 (slightly or moderately); 2 (presence or a lot).

Loc. mod. (Location trait): B (Basal); M (Median); A (Apical); D (Diffuse).

Foliage color Int. (Foliage color Intensity).

refined those expressions into "reductions", keeping their essential meanings without interpretation. They then created categories that integrated all visual dimensions evoked by the subjects such as shape, branching, foliage density, etc.; meaningless or uninformative and hedonic expressions were discarded. In the cases of overly ambiguous synonyms or antonyms, a non-over-grouping and non-over-interpretation strategy was chosen. They also associated traits related to intensity, color, location and shape with these categories in order to clarify the meaning of each reduction.

The combination of categories and traits for the reduction transcoding are subsequently referred to as "lexical items" (see Table 2 for some transcoding examples). If several reductions for a description were transcoded into the same lexical item, duplicates were removed to keep only one of them per description. The lexical items were then reallocated to each product. The magnitude of each lexical item was computed over the products as the maximum number of occurrences for one product minus the minimum. Only those with a magnitude greater than 3 were kept for the mapping interpretation. To project lexical items on the product space for interpreting MDS dimensions, Pearson correlations between lexical items (number of occurrences for each product) and MDS dimensions (product coordinates on each dimension) were computed (Faye et al., 2004).

\section{Statistical analysis}

Statistical analyses were performed with the R environment ( $R$ Development Core Team., 2012). The following packages were used: MASS (Venables \& Ripley, 2002) for non-metric MDS; FactoMineR (Husson, Josse, Lê, \& Mazet, 2013) for RV computing; stats for HCA (R Development Core Team, 2012); and mcclust (Fritsch, 2012) for RI computing.

\section{Results}

\section{Sorting analysis}

The stress scree plot (Fig. 2) showed that no clear rupture could be detected for the three stress patterns. Nevertheless, a stress of 0.1 is considered to be sufficient to determine an acceptable fit with the observed dissimilarity (Faye et al., 2004; Krzanowski \& Marriott, 1994). With a stress of 0.09 for each panel and 0.08 for the pooled panel, the five-dimensional configurations fulfilled this criterion and were kept for subsequent analysis.

The five dimensional product mapping obtained with panel 1 and those with panel 2 returned a highly significant RV equal to 0.75 ( $p$-value $<0.001$ ). From different studies, Vidal, Silva Cadena, and Correa (2014) reported that "the minimum RV value that has been considered as indicator of good agreement between sample configurations ranges from 0.65 to 0.85 ". They also argued that if two mappings of same products return a significant RV, then it can be concluded that information gathered in the two mappings is similar. Despite this, RV interpretations should be done with care since it is dependent of the data dimensionality and inertia (Ares et al., 2014; Tomic, Forde, Delahunty, \& Næs, 2013). In the present study, the RV value and its significance suggested two rather coherent product mappings with some differences. In order to precise this proximity, a HCA on each panel data was performed on their respective dissimilarity matrix. The two resulting product partitions obtained showed a quite good crosschecking (Table 3): for both panels, five core groups of products could be distinguished, and only seven products out the 40 were not classified similarly. With a RI $=0.88$, we can assume that the two partitions as the product mappings shared a quite large amount of similar information. We thus concluded that the sorting reproducibility was good enough to consider a global mapping of the pooled panel data without occulting too much information.

Equally, the pooled panel data also made it possible to distinguish the previous five groups of virtual rose bushes represented on the MDS mapping (Fig. 3). The first dimension (36.8\% of the total inertia) opposes Groups 1 and 2-Groups 5 and 4 . The second dimension (26.4\%) splits Groups 1 and 4 from the others. The third and fourth dimensions (15.6 and 11.7\%) both separate Group 3 from Groups 5 and 1 and from Groups 2 and 4 . With this partition, the most representative virtual rose bushes are R_20, R_08, R_04, R_06 and R_25 for Groups 1 to 5, respectively (Videos 1, 2, 3, 4 and 5, respectively. See Fig. 4 for a picture of the virtual rose bushes).

\section{Description analysis and transcoding for product mapping interpretation}

Using the descriptions given by the subjects allowed a sensory interpretation of the product space. After removing hedonic (e.g., 


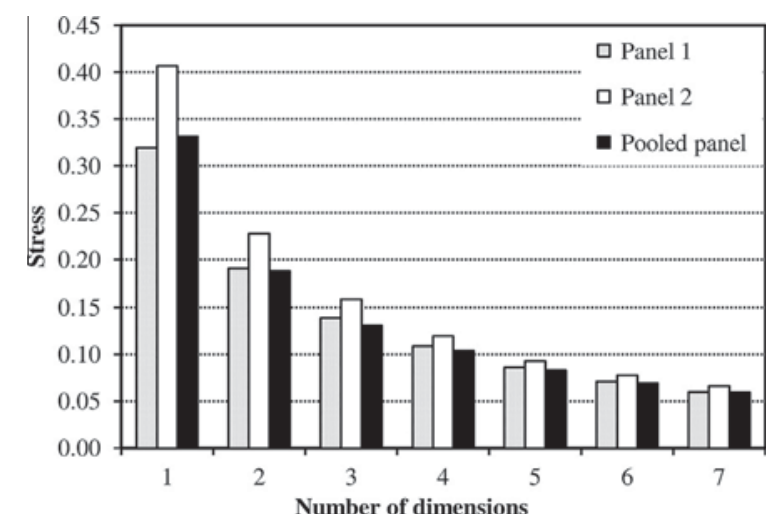

Fig. 2. Stress scree plot: stress value according to the number of dimensions involved in the MDS procedure carried out on the data for each panel and for the pooled panel.

Table 3

Confusion matrix for the 40 virtual rose bushes according to the two partitions obtained from product clustering of each panel data. Products that were not classified similarly between the two partitions obtained are pointed out in bold.

\begin{tabular}{|c|c|c|c|c|c|c|}
\hline \multirow{2}{*}{$\begin{array}{l}\text { Panel } 2 \\
\text { partition }\end{array}$} & \multicolumn{5}{|c|}{ Panel 1 partition } & \multirow[t]{2}{*}{ Total } \\
\hline & $\begin{array}{l}\text { Group } \\
1\end{array}$ & $\begin{array}{l}\text { Group } \\
2\end{array}$ & $\begin{array}{l}\text { Group } \\
3\end{array}$ & $\begin{array}{l}\text { Group } \\
4\end{array}$ & $\begin{array}{l}\text { Group } \\
5\end{array}$ & \\
\hline Group 1 & 6 & 2 & 3 & & & 11 \\
\hline Group 2 & & & 7 & & & 7 \\
\hline Group 3 & & 6 & & 2 & & 8 \\
\hline Group 4 & & & & 8 & & 8 \\
\hline Group 5 & & & & & 6 & 6 \\
\hline Total & 6 & 8 & 10 & 10 & 6 & 40 \\
\hline
\end{tabular}

"interesting aspect", "aesthetic", "unpleasant"), meaningless or misunderstood expressions (e.g., "model", "one axis", "fructification with two axes") and lexical items in duplicate, 631 reductions out of the 703 initial ones isolated from the descriptions given by the subjects were kept for subsequent analysis. Each reduction was associated with one of the 81 lexical items, each composed of an association of one of the 24 description categories indicated by the experts and the traits necessary to specify their characteristics. The most recurrent description categories (Fig. 5) concerned the branching of the rose bushes ( $16.5 \%$ of the reductions), their symmetry $(14.7 \%)$, their compactness $(13.9 \%)$, their shape $(11.7 \%)$, their height (9.8\%) and their foliage color intensity (7.8\%). Foliage density, homogeneity and fruit quantity were the second most prevalent categories ( 3.6 to $4.3 \%$ for each). Nonetheless, a significant difference in the distribution of the description categories observed for the two panels (data not shown) was found (Fisher's exact test for count data returned a $p$-value $<0.001$ ). Panel 1 was more focused on foliage and fruit color properties, the homogeneity, and the order 1 stem length (the major axis of the plant) than panel 2, more focused on the foliage density, the fruit quantity, and the shape regularity.

After reallocation of the 81 lexical items to the virtual rose bushes, 25 of them fulfilled the chosen magnitude criterion of 3 and were kept for the product mapping interpretation. Both represented $76.2 \%$ of the 3045 occurrences observed for all lexical items. On the basis of the correlation analysis between the lexical items and the MDS dimensions (Fig. 6; the fifth dimension is not clearly related to any lexical items and is not shown). The product clustering (Fig. 3) could be thus interpreted: Group 1 is composed of compact rose bushes, symmetrical, highly branched from bottom to top, homogeneous, small, regularly-shaped and very leafy; Group 2 differs from Group 1 by a greater height, greater branching and compactness on top and an absence of basal branching; Group 4 is composed of asymmetric rose bushes, slightly leafy, not very branched, heteroge- neous, loose, frail and top-sided; Group 5 differs from Group 4 by a vertically compressed or Y shape, an absence of basal branching, long stems and a non-characterization by asymmetry; Group 3 is the most heterogeneous and forms an intermediary group between Groups 2 and 4. It is mainly composed of tall rose bushes, more branched on the top than on the bottom; some are asymmetric and others have heterogeneous branch lengths or a lighter foliage.

So, the main differences explaining the product space structuration sat on the branching degree and location, the foliage density, the compactness, the symmetry, the shape and its regularity, the homogeneity, and the height. Interestingly, "Homogeneity_2" and "Shape_regularity_2" were closely linked and both strongly opposed to "Homogeneity_0". Both were not part of the most recurrent description categories but they were well-linked to the first MDS dimension like for the quantitative lexical items of "Branching", "Foliage density" and "Compactness". This implies that uniformity of the plant's facets along the rotation according general shape and or eventually more focused characteristics was considered by the subjects. This consideration was related to the major direction of the product space which reflects also in a same way the quantitative level of compactness, branching and foliage density of the virtual rose bushes.

\section{Discussion}

The subjects performed the task in an hour and half to two hours. They did not express a particular annoyance or boredom showing that they are able to deal with videos of rotating virtual plant and that such an experiment is easily doable. Non-metric MDS product mappings showed that subjects perceived differences and similarities between the virtual rose bushes that can be resumed in a five dimensional space. Using the $\mathrm{RV}$, sorting results of the two panels were judged as reflecting a rather good concordance. However, RV interpretations and comparisons with other studies should be done with care since both the data dimensionality and the size of difference among the products have an impact on this index. This stress yet highlighted need of other criteria less sensitive and more suitable than the RV, but also than the modified RV (or RV2), to measure similarity between data matrices (Ares et al., 2014; Tomic et al., 2013; Vidal et al., 2014). Anyway, in this experiment, a similar five groups partitioning was found for both panels $(R I=0.88)$. Therefore, the sorting was judged to be sufficiently reproducible to consider a pooled panel for which a similar product partitioning was also found. Panel results comparison for identical sensory tasks is an usual strategy, for example : to study expertise level effect (Chollet et al., 2011), or for cross-cultural studies (Bécue-Bertaut \& Lê, 2011). Here, it appeared also as an interesting strategy to investigate the global task reproducibility.

From a standpoint on sensory methodology for the sample size, as suggested by Faye et al. (2004), a sorting task of products tasted in the mouth is more tiring than a sorting of products evaluated on visual and tactile properties. Here, subjects' feelings and time needed to complete the task did not suggest an oversized stimuli sample. Using beers as stimuli, Chollet et al. (2011) addressed the sample size effect on sorting task efficiency, and concluded that an optimum sample size around 12 products allowed better results. The authors argued that the number of products that can be efficiently sorted strongly depends of the product nature, the resemblance degree between products, and of the short-term memory abilities of the subjects. On this particular point, for a sorting task or other sensory methods, further investigations should be done to better understand plant sample size effects on the product characterization and the panel(ist) performance. Nevertheless, for a sorting task, so as not to take advantage of the subjects' shortterm memory, and for improving the test usability, it would 

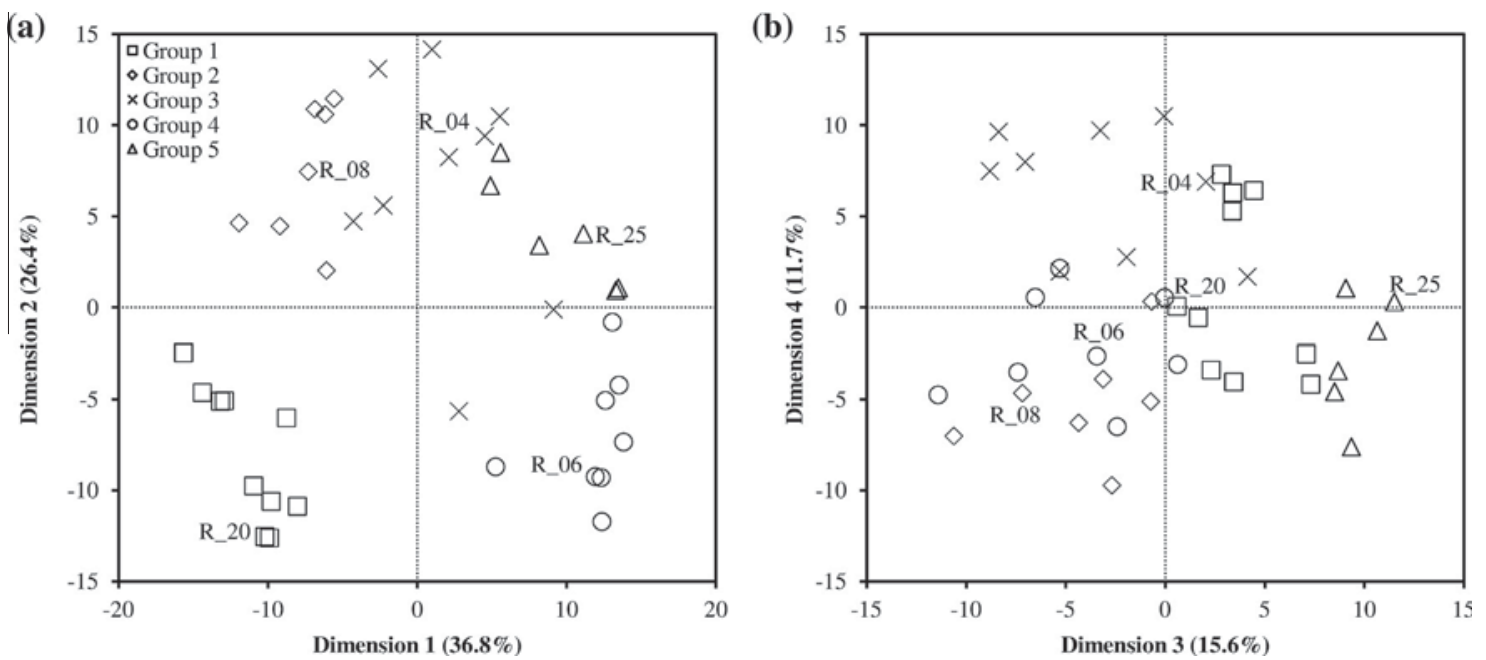

Fig. 3. MDS product mapping and groups identified by clustering: (a) on the first two dimensions; (b) on dimensions 3 and 4 . Representative products of the groups are indicated by their name next to their markers.
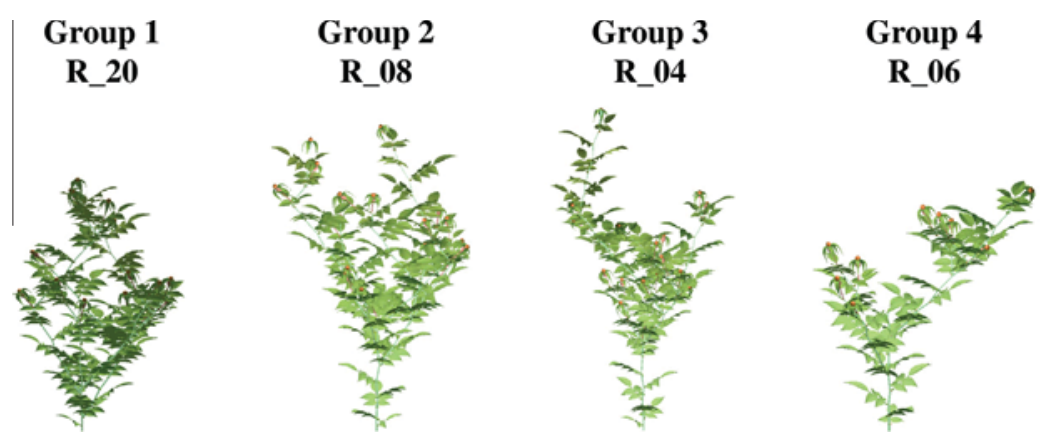

\section{Group 5

Fig. 4. The most representative virtual rose bush of each group identified by clustering.

perhaps be possible to improve the setup by using a real simultaneous presentation of the virtual plants. For example, a presentation on a large tactile screen with the possibility to sort directly the videos simultaneously played would be a valuable task improvement.

From an agronomic point of view, as mentioned by DemotesMainard et al. (2013), interplant variability of various architectural parameters within a rose bush crop is quite high. Here, with only two architectural parameters that govern branching and axis length, the number of stimuli used $(n=40)$ was sufficient to generate visual differences perceptible by the human eye. This stresses that plants' visual appearance is effectively conditioned by their architecture. Thus, architectural within-crop variability could constitute a product differentiation source that should be studied for a better crop control as required either to increase crop uniformity, or contrary, to generate new product segmentations. Nonetheless, transposition and evaluation on plants at various development stages and with more than two variable architectural parameters should be done to investigate and confirm this.

The verbalization task allowed for a rough description of the virtual rose bushes showing a perceptual structuration with large differences between at least four out the five identified groups. These differences are mainly based on the general appearance of the plants rather than on precise characteristics of the aerial organs. Except for the buds, which are barely visible, and for the thorns, not apparent on these virtual plants, as the flowers, the vocabulary obtained and used to interpret the product mapping is effectively reliable for the attributes dealt with Boumaza et al. $(2009,2010)$ obtained by another methodology for several cultivars and used for the 'Radrazz' alone (Huché-Thélier et al., 2011).This stresses the need to enhance some virtual organ faithfulness to be more exhaustive. Nonetheless, in these studies, the plant height was not being part of the sensory lexicon as reported here. Else, in the initial sensory attribute list of Boumaza et al., "Habit evenness", the attribute the most connected to a 3D perception of the plant was proposed with this definition: “'an even habit' means that the plant organs are evenly spread over the plant, and one sees the same thing when turning the plant.", which was rejected because of unambiguity requirements. In the presented results, the description categories "Shape regularity" and "Homogeneity" cover well this previous "Habit evenness" attribute. Lexical items of these description categories were unequally cited by the two panels highlighting some differences in the vocabulary employed by the subjects, but lexical item projection on the product mapping showed that they were in fact closely linked. Moreover they were well related to the first dimension of the product mapping like for quantitative lexical items of "Branching", "Foliage density" and "Compactness" categories, which presented also links between them. Thus, regarding the meaning and original terms they covered, it would have been possible to merge "Shape regularity" and "Homogeneity" together since both depict an integration of the plant 3D by the assessment of the shape uniformity and or uniformity of others characteristics along the plant rotation. So, using rotating plant videos, this study showed that subjects were able to naturally integrate and verbalize plant facet variations. Concerning the proximity of the only quantitative lexical items related to "Compactness", "Branching" and "Foliage 


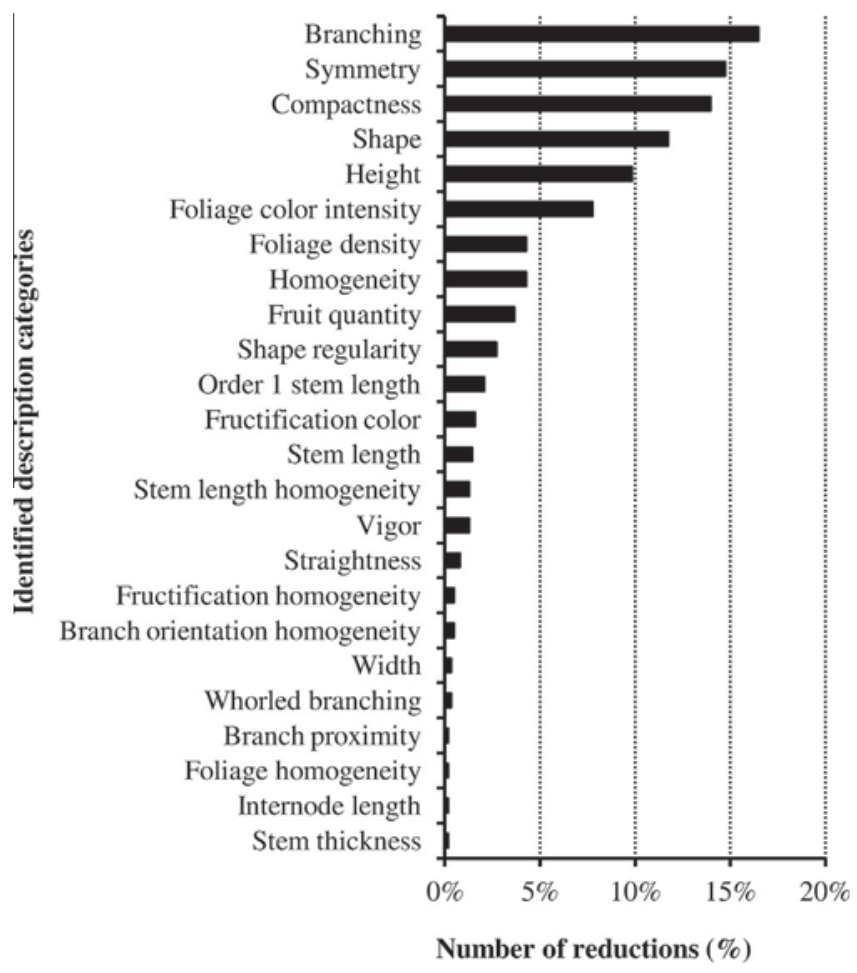

Fig. 5. Number of reductions (\%) by identified description categories.

density", this relation was also reported by Boumaza et al. (2009). Previous authors preconized to use "Twiggy plant", and "Foliage thickness" but not "Compactness" for independence requirement. As argued by the authors, the plant compactness depends of the foliage quantity and the branching degree. However, the size and the 3D shape of the plant could be seen also as compactness determinants. This suggests the need of a better understanding and definition of this multidimensional characteristic frequently misused in the ornamental sector, but also, both facts stress again the delicacy of free description analyzes and sensory attribute list elaboration (Boumaza et al., 2009; Symoneaux et al., 2012).

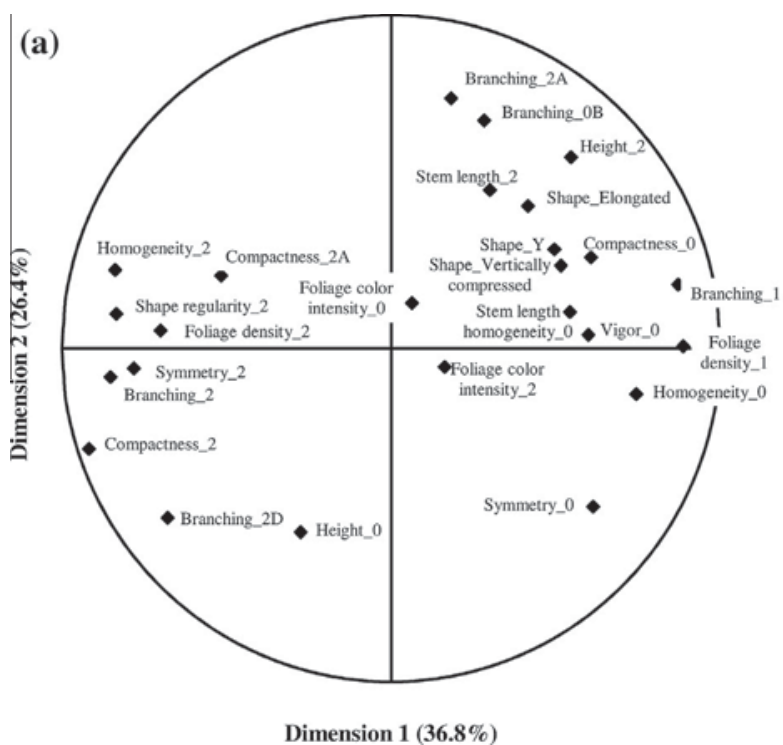

Finally, a labeled sorting task was a suitable tool to explore quickly the product space and highlight its structuration. The task allowed highlighting representative products and a rich descriptive lexicon basis. As reported already, this kind of preliminary task provides much valuable information to set up subsequent sensory experiments (Chollet et al., 2011; Giboreau, Navarro, Faye, \& Dumortier, 2001). Indeed, for a better characterization of such a product space that presents continuous variations, scale-based methods as the sensory profile appear to be more suitable than categorization ones. This is particularly true especially for subsequent envisaged studies on correlation researches between sensory and instrumental data obtained from the plant architecture and images (Chéné et al., 2012; Santagostini et al., 2014). With further complementary researches, integrated methodological tools to better fulfill consumers' expectations can be sketched for forward thinking growers. The genesis of such tools can stand on the advantages provided by virtual plant modeling devices which integrate genotype and environment interactions' effects on architectural parameters, and their within crop variability (Crespel et al., 2014; Demotes-Mainard et al., 2013). Such devices associated with instrumental 3D characterization related to visual sensory properties could provide interesting support decision tools for guiding cultural practices toward ornamental plants with specified visual characteristics.

Also, other research areas could also be highly interested by the alternatives that allow virtual modeling devices especially, e.g. : to get more faithful and more normalized product presentation, to get or control easily intrinsic product parameters, to get quickly large sample sets for fulfilling experimental and statistical requirements, and so on. As an example in another domain, Griffiths and Kulke (2002) presented a study in which virtual modeling and video recording have already been used for sensory evaluation of clothing movement of different fabrics in order to develop sensory descriptors and to relate visual descriptors to some fabric mechanical properties.

\section{Conclusions}

In this study, the use of rotating virtual rose bush videos as stimuli for a sensory evaluation of their visual appearance was investigated. Virtual plants were obtained through a structural

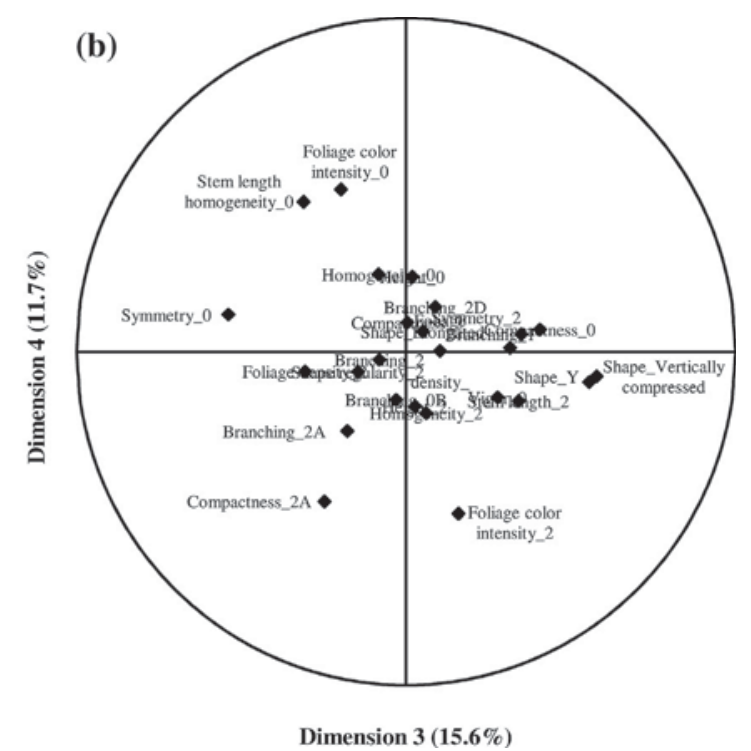

Fig. 6. Correlations between lexical items and: (a) the first two MDS dimensions; (b) the third and fourth MDS dimensions. 
and probabilistic modeling process reflecting the variability of bud breaks location and axes length within a five-month old 'Radrazz' crop. The sensory evaluation consisted in a labeled sorting task of 40 videos performed by two panels with different background characteristics, mainly of occupational status and age.

Comparing results of the two panels was an effective way for assessing and showing the global task reproducibility. Even if few differences in the product partitions and the frequencies of the description categories have been highlighted, outcomes obtained in each panel were globally similar. While only considering the variability of two core architectural development parameters in the modeling process, the task enabled to assert that within a rose bush crop, this variability is sufficient to generate substantial visual differences structuring the product space.

Using rotating plant videos allowed the subjects to integrate three-dimensional properties that are not accessible using only one plant facet. This stresses the importance to consider the plant 3D configuration, and the need to better investigate how this could be integrated with sensory and other instrumental methods. However, even if some improvements can be considered like using large tactile screens, using videos of rotating virtual plant as stimuli for a labeled sensory task is quite feasible. Also, it does not seem to be inappropriate for a sensory profile.

Finally, this experiment showed that: (i) rotating virtual plants could be used as stimuli; (ii) high visual differences can be perceived within a single rose bush crop; (iii) using rotation, the subjects can integrate the plant 3D in the characterization. So, knowing that the product space presents large perceptible differences, this experiment provided a solid basis for more rapid panel formation in order to establish a sensory profile for the same type of products. A labeled sorting task is therefore an interesting tool for: (i) quickly exploring the product space; (ii) the identification of product references; and (iii) drawing-up preliminary attribute list.

\section{Acknowledgments}

The authors thank the Pays de la Loire Regional Council for their financial support, L. Crespel and Ph. Morel for their expert opinions, G. Wagman for the English correction of the manuscript. Finally, the authors thank all of the people who took part in the sensory test, and also the two anonymous reviewers for their relevant advices on the manuscript.

\section{Appendix A. Supplementary data}

Supplementary data associated with this article can be found, in the online version, at http://dx.doi.org/10.1016/j.foodqual.2014.06. 008.

\section{References}

Abdi, H., Valentin, D., Chollet, S., \& Chrea, C. (2007). Analyzing assessors and products in sorting tasks: DISTATIS, theory and applications. Food Quality and Preference, 18(4), 627-640. http://dx.doi.org/10.1016/j.foodqual.2006.09.003.

Ares, G., Antúnez, L., Giménez, A., Roigard, C. M., Pineau, B., Hunter, D. C., et al. (2014). Further investigations into the reproducibility of check-all-that-apply (CATA) questions for sensory product characterization elicited by consumers Food Quality and Preference, 36, 111-121. http://dx.doi.org/10.1016/ j.foodqual.2014.03.010.

Bijmolt, T. H. A., \& Wedel, M. (1995). The effects of alternative methods of collecting similarity data for Multidimensional Scaling. International Journal of Research in Marketing, 12(4), 363-371. http://dx.doi.org/10.1016/0167-8116(95)00012-7.

Boumaza, R., Demotes-Mainard, S., Huché-Thélier, L., \& Guérin, V. (2009). Visual characterization of the esthetic quality of the rosebush. Journal of Sensory Studies, 24(5), 774-796. http://dx.doi.org/10.1111/j.1745-459X.2009.00238.x.

Boumaza, R., Huché-Thélier, L., Demotes-Mainard, S., Le Coz, E., Nathalie, L. Pelleschi-Travier, S., et al. (2010). Sensory profiles and preference analysis in ornamental horticulture: The case of the rosebush. Food Quality and Preference, 21(8), 987-997. http://dx.doi.org/10.1016/j.foodqual.2010.05.003.
Bécue-Bertaut, M., \& Lê, S. (2011). Analysis of multilingual labeled sorting tasks: Application to a cross-cultural study in wine industry. Journal of Sensory Studies, 26(5), 299-310. http://dx.doi.org/10.1111/j.1745-459X.2011.00345.x.

CamStudio. (n.d.). CamStudio (Version 2.00). Retrieved from http://camstudio.org.

Chéné, Y., Rousseau, D., Lucidarme, P., Bertheloot, J., Caffier, V., Morel, P., et al. (2012). On the use of depth camera for 3D phenotyping of entire plants. Computers and Electronics in Agriculture, 82, 122-127. http://dx.doi.org/10.1016/ j.compag.2011.12.007.

Chollet, S., Lelièvre, M., Abdi, H., \& Valentin, D. (2011). Sort and beer: Everything you wanted to know about the sorting task but did not dare to ask. Food Quality and Preference, 22(6), 507-520. http://dx.doi.org/10.1016/j.foodqual. 2011.02.004.

Crespel, L., Le Bras, C., Relion, D., \& Morel, P. (2014). Genotype $\times$ year interaction and broad-sense heritability of architectural characteristics in rose bush. Plant Breeding. http://dx.doi.org/10.1111/pbr.12157.

Crespel, L., Sigogne, M., Donès, N., Relion, D., \& Morel, P. (2013). Identification of relevant morphological, topological and geometrical variables to characterize the architecture of rose bushes in relation to plant shape. Euphytica, 191(1), 129-140. http://dx.doi.org/10.1007/s10681-013-0902-6.

Demotes-Mainard, S., Bertheloot, J., Boumaza, R., Huché-Thélier, L., Guéritaine, G., Guérin, V., et al. (2013). Rose bush leaf and internode expansion dynamics: Analysis and development of a model capturing interplant variability. Frontiers in plant science, 4(418). http://dx.doi.org/10.3389/fpls.2013.00418.

Favre, P., Guéritaine, G., Andrieu, B., Boumaza, R., Demotes, S., Fournier, C., et al. (2007). Modelling the architectural growth and development of rosebush using L-systems. Poster presented at the Workshop Growth Phenotyping and Imaging in Plants. France: Montpellier.

Faye, P., Brémaud, D., Durand Daubin, M., Courcoux, P., Giboreau, A., \& Nicod, H. (2004). Perceptive free sorting and verbalization tasks with naive subjects: An alternative to descriptive mappings. Food Quality and Preference, 15(7-8), 781-791. http://dx.doi.org/10.1016/j.foodqual.2004.04.009.

Faye, P., Courcoux, P., Giboreau, A., \& Qannari, E. M. (2013). Assessing and taking into account the subjects' experience and knowledge in consumer studies. Application to the free sorting of wine glasses. Food Quality and Preference, 28(1), 317-327. http://dx.doi.org/10.1016/j.foodqual.2012.09.001.

Fritsch, A. (2012). mcclust: Process an MCMC sample of clusterings (Version 1.0). Retrieved from http://cran.r-project.org/package=mcclust.

Giboreau, A., Navarro, S., Faye, P., \& Dumortier, J. (2001). Sensory evaluation of automotive fabrics: The contribution of categorization tasks and non verbal information to set-up a descriptive method of tactile properties. Food Quality and Preference, 12(5-7), 311-322. http://dx.doi.org/10.1016/S09503293(01)00016-7.

Griffiths, P., \& Kulke, T. (2002). Clothing movement-visual sensory evaluation and its correlation to fabric properties. Journal of sensory studies, 17(3), 229-255. http://dx.doi.org/10.1111/j.1745-459X.2002.tb00345.x.

Heuvelink, E., Tijskens, P., \& Kang, M. Z. (2004). Modelling product quality in horticulture: An overview. In M. Fink \& C. Feller (Eds.), Proceedings of the international workshop on models for plant growth and control of product quality in horticultural production (pp. 19-30). Postdam, Germany: Acta Horticulturae (ISHS).

Hubert, L., \& Arabie, P. (1985). Comparing partitions. Journal of Classification, 2(1), 193-218. http://dx.doi.org/10.1007/BF01908075.

Huché-Thélier, L., Boumaza, R., Demotes-Mainard, S., Canet, A., Symoneaux, R., Douillet, O., et al. (2011). Nitrogen deficiency increases basal branching and modifies visual quality of the rose bushes. Scientia Horticulturae, 130(1), 325-334. http://dx.doi.org/10.1016/j.scienta.2011.07.007.

Husson, F., Josse, J., Lê, S., \& Mazet, J. (2013). FactoMineR: Multivariate exploratory data analysis and data mining with $\mathrm{R}$ (Version 1.21). Retrieved from http:// cran.r-project.org/package=FactoMineR.

Husson, F., Josse, J., \& Pagès, J. (2010). Principal component methods - hierarchical clustering - partitional clustering: Why would we need to choose for visualizing data? Technical report. Applied Mathematics Department. Agrocampus Ouest. Retrieved from http://factominer.free.fr/docs/HCPC_husson_josse.pdf.

Josse, J., Pagès, J., \& Husson, F. (2008). Testing the significance of the RV coefficient. Computational Statistics \& Data Analysis, 53(1), 82-91. http://dx.doi.org/ 10.1016/j.csda.2008.06.012.

Karwowski, R., \& Prusinkiewicz, P. (2004). The L-system-based plant-modeling environment L-studio 4.0. In C. Godin, J. Hanan, W. Kurth, A. Lacointe, A. Takenaka, P. Prusinkiewicz, T. De Jong, C. Beveridge \& B. Andrieu (Eds.), Proceedings of the 4th international workshop on functional-structural plant models (pp. 403-405). Montpellier, France. UMR AMAP.

Krzanowski, W. J., \& Marriott, F. H. C. (1994). Multivariate analysis: Part I, distributions, ordination and inference. New York: Kendall.

Morel, P., Galopin, G., \& Donès, N. (2009). Using architectural analysis to compare the shape of two hybrid tea rose genotypes. Scientia Horticulturae, 120(3), 391-398. http://dx.doi.org/10.1016/j.scienta.2008.11.039.

R Development Core Team. (2012). R: A language and environment for statistical computing (Version 2.15.2). Vienna, Austria: R Foundation for Statistical Computing. Retrieved from http://www.R-project.org/.

Santagostini, P., Demotes-Mainard, S., Huché-Thélier, L., Leduc, N., Bertheloot, J., Guérin, V., et al. (2014). Assessment of the visual quality of ornamental plants. Comparison of three methodologies in the case of the rosebush. Scientia Horticulturae, 168, 17-26. http://dx.doi.org/10.1016/j.scienta.2014. 01.011 .

Stone, H., Sidel, J., \& Singleton, R. C. (1974). Sensory evaluation by quantitative descriptive analysis. Food Technology, 28(11), 24-34. 
Strigler, F., Touraille, C., Sauvageot, F., Barthélémy, J., \& Issanchou, S. (2009). Les épreuves discriminatives et descriptives. In F. Depledt \& SSHA (Eds.), Évaluation sensorielle : Manuel méthodologique (3 ed.,pp. 99-197). Paris: Lavoisier.

Symoneaux, R., Galmarini, M. V., \& Mehinagic, E. (2012). Comment analysis of consumer's likes and dislikes as an alternative tool to preference mapping. A case study on apples. Food Quality and Preference, 24(1), 59-66. http:// dx.doi.org/10.1016/j.foodqual.2011.08.013.

Tomic, O., Forde, C., Delahunty, C., \& Næs, T. (2013). Performance indices in descriptive sensory analysis - A complimentary screening tool for assessor and panel performance. Food Quality and Preference, 28(1), 122-133. http:// dx.doi.org/10.1016/j.foodqual.2012.06.012.
Varela, P., \& Ares, G. (2012). Sensory profiling, the blurred line between sensory and consumer science. A review of novel methods for product characterization. Food Research International, 48(2), 893-908. http://dx.doi.org/10.1016/j.foodres.2012. 06.037.

Venables, W. N., \& Ripley, B. D. (2002). Modern applied statistics with S (4 ed.). New York: Springer.

Vidal, L. Silva Cadena, R. Correa, S. Ábalos, R. A., Gómez, B., et al. (2014). Assessment of global and individual reproducibility of projective mapping with consumers. Journal of Sensory Studies, 29(1), 74-87. http://dx.doi.org/10.1111/ joss. 12083 . 